Available as preprint at https://doi.org/10.31235/osf.io/ea9jm

\title{
Communication on COVID-19 to community - measures to prevent a second wave of epidemic
}

\author{
Boris Bikbov, MD, Ph.D. ${ }^{1}$, Alexander Bikbov, Ph.D. ${ }^{2}$ \\ ${ }^{1}$ Istituto di Ricerche Farmacologiche Mario Negri IRCCS, Bergamo, Italy \\ ${ }^{2}$ Ecole des Hautes Etudes en Sciences Sociales, Paris, France
}

Short title: COVID-19 communication to community

Word count: 1928

Number of references: 53

Corresponding authors:

Boris Bikbov, MD, Ph.D.

Istituto di Ricerche Farmacologiche Mario Negri IRCCS,

Via G.-B. Camozzi 3 - 24020, Ranica, Bergamo, Italy

Tel: +390354535305

Fax: +390354535371

Email: boris.bikbov@gmail.com

Alexander Bikbov, PhD

Ecole des Hautes Etudes en Sciences Sociales

54 bd Raspial - 75006, Paris, France

Tel: +33149548308

Email: abikbov@gmail.com 


\section{Introduction}

COVID-19 pandemic is rapidly spread over the planet,[1] and countries are tackling to limit its progression by different approaches.[2] A variety of community mitigation strategies are applied,[3] however, some recent medical discoveries are not widely communicated to the public, and knowledge and attitudes about the infection is not routinely measured in community - while it could be crucial to prevent a second wave of epidemic. The shortage of publicly shared knowledge stands problematic not only in the context of growing concerns about fake news,[4] but also in the context of distrust towards public institutions[5] promoting norms of individual behavior and coordinating community cooperation during the epidemic.

\section{Community awareness on quarantine threshold}

Current knowledge and blind-spots concerning COVID-19 epidemic play a crucial role both in choice of institutionally approved "top-down" medical policies and in grass-roots strategies adopted by communities. Notably, there is a knowledge gap between widely communicated data on time thresholds and recent scientific findings, that primary concerns incubation and viral shedding periods.

The maximal incubation period as 14 days was widely communicated to the public by WHO[6] and mass media, but modeling study estimated that 1 in 100 infected patients will develop symptoms after 14 days of active monitoring or quarantine,[7] and some scientific reports suggest it could be extended up to 24 days[8][9] (in one of these 
manuscripts this maximal duration was indicated in the preprint[8] but changed to median and interquartile duration in the accepted article[10]).

The viral RNA shedding (estimated by real-time reverse transcriptase-polymerase chain reaction (RT-PCR)) varies by severity of infection, and China data from hospitalized 137 survivors indicate the median duration as 20 days (interquartile range 17-24) and maximal duration as 37 days.[11] In another study of 46 patients with mild infection not requiring ICU treatment the duration was shorter, with $90 \%$ achieving viral RNA clearance by 10 post-onset day, but some of them only at 15 day, while in 30 patients with severe infection viral RNA shedding continued up to 25 days.[12] Thus, between studies estimate of maximal duration of viral RNA shedding could vary more than 1.5-fold in severe cases, and probably this is also true for the mild infection.

As we know from the largest published experience of China,[13] 81\% of patients have mild clinical signs and symptoms, and in case of hospital overwhelm could be treated at home. Almost $50 \%$ of patients had no fever (>37.5 C) at admission to the hospital, and $11-15 \%$ of mild cases had no fever during the whole hospitalization, over a third had no cough, and almost $80 \%$ had no dyspnea[10][12] - that potentially could lead to noncompliance with stay-at-home regimen. Indeed, modeling study estimated that $86 \%$ of all infected persons were undocumented prior to travel restrictions,[14] and Chinese researchers suggest that $59 \%$ of the infected individuals were not being tested, and probably continued to follow a routine lifestyle. A substantial proportion (18-30\%) of infected individuals are completely asymptomatic,[15] even there is much uncertainty whether they could infect others. Moreover, shortage of diagnostic tests could lead to late COVID-19 diagnostic even in symptomatic medical personnel.[16] Considering risks associated with such epidemiological uncertainty and possibility of quick infection spread by both symptomatic and asymptomatic bearers, many national and local 
governments set highly restrictive measures limiting personal social mobility of the whole population.[2]

No representative data are available on awareness about the aforementioned medical facts, but our sporadic communication with either healthy general public individuals or persons who had one-week febrile fever without hospitalization and with no RT-PCR test for SARS-CoV-2 revealed that none of them were aware about possibility of incubation or viral RNA shedding period longer than 14 days. In opposite to the longer viral RNA shedding, the median duration of fever was 12 days among hospitalized patients,[11] and could be even shorter in less severe patients who stay at home without RT-PCR testing. For many individuals disappearance of fever could symbolize the end of acute phase, especially if cough is decreasing or absent. Communication of these facts could be especially important to the most socially active persons, who could have higher chances to be infected, and in case of incomplete recovery and return to high social activity (including possible violations of the social distancing measures) they could play a role of moving force for secondary wave of epidemic.

Aforementioned facts have strong consequences for the epidemic process, and highlight the need to communicate these data wider to the general population. Current stay-at-home policy is widely promoted, but even in the most affected Lombardy Region in Italy[17] up to $40 \%$ of population might continue to move outside their homes according to the mobile phones tracking,[18] although it remains unclear whether this number related just to movement to local grocery stores, sport activity, relocation to socially significant work, or also reflects undesirable inter-personal interactions or unnecessary long-distance journeys. Seeing as a sign of irresponsible attitude "from below", this percentage pushes to harden restrictive measures over population and amplify police controls. These phenomena occurs in the context of a substantial pre- 
epidemic distrust of the population to government authority, with Italy and France showing the scepticism concerning public institutions (66-86\%), national economy (6683\%) and European future (44-55\%) among the highest in the EU in Eurobarometer survey.[19] Under such circumstances, public institutions could strengthen their confidence by consistent sharing of latest and detailed scientific knowledge about COVID-19, in addition to mainly paternalistic hardening of stay-at-home control.

\section{Community engagement to fight with epidemic}

Involvement of different community structures, starting from local authorities to small grocery stores (setting up home delivery) to volunteering assistance networks, is exceptional, with a major respect of the adopted security restrictions. The governmental communication with general public seems reasonably paternalistic based on unidirectional instructions on prevention measures, information about economic incentives, and core numbers of COVID-19 outbreak. However, little is known about the perception of these communications by general public, everyday practices of adhesion to these rules by different social groups, psychological patterns of copping with restrictive measurements in different countries and groups. In fact, by March 21 we found only two articles among the 2249 publications on COVID-19[20] in the WHO database and one article not yet indexed there regarding knowledge, attitudes and practices in community. In China, respondents had high adherence to isolation measures, even if $8.5 \%$ could not achieve "do not go to crowded and closed places" measure, but a low awareness rate of the atypical symptoms of COVID-19.[21] In Saudi Arabia, experience on MERS-CoV indicates almost a half of population were not aware about upper respiratory symptoms during infection, the need of preventive hand 
washing and that disease is transmitted by infected people.[22] Survey of almost 6,000 respondents in United States and United Kingdom indicated generally good knowledge of the main mode of disease transmission and common symptoms, but $15-20 \%$ were not aware about respiratory symptoms of COVID-19 infection, 19-25\% wrongly assumed not relevant symptoms, 19-25\% did not know how persons could be infected, and $7-14 \%$ were not aware about preventive measures.[23]

A dozen of articles evaluated psychological response ([24][25][26][27][28][29][30] just to mention a few), with the most important finding in the context of current analysis that persons who perceive to having low risk of infection or complications are less likely to change their social behavior and prone to disregard recommendations for social distancing.[31] Analysis of MERS-CoV outbreak indicates that both affective and cognitive risk perceptions decreased over time,[32] which may also be relevant in group behavior during the current COVID-19 epidemic.

Considering the shortage of data on these issues, we advocate to perform both quantitative and qualitative sociological studies to monitor the community perception and adherence to preventive measures. Complimentary to this monitoring strategies include evaluation of search engine queries[33] and big data analysis of social media. Taiwan and South Korean governments have implemented community-oriented strategy of real-time information through text messaging about the virus propagation that zooms the contamination cases to the level of city districts and even of condominiums[34][35] resulted from massive preventive testing.[36] Experimental mobile phone-based web survey with artificial intelligence processing suggests early identification of the high-risk persons with clinical symptoms or history of contacts, with subsequent quarantine recommendation.[37] The later methods have yet a tangible potential of consent and privacy issues, and their use beside the range of prediction needs a closer examination. 


\section{Vulnerable social groups}

The COVID-19 infection has higher complication rates in elderly population. Children, even if generally having mild clinical symptoms, find themselves in the increased risk of physical and mental impacts of quarantine,[38] and require specific approach for communication.[39] However, some age unrelated social groups are especially vulnerable during the epidemic. This concerns persons with low health literacy,[40] international migrant workers[41] with estimated global number as 150 million, international students,[42] persons in assisted living and nursing homes, persons with intellectual or sensorial disabilities,[43] refugees,[44][45] homeless people,[46] prisoners.[47] These groups are disempowered in face of the epidemic and urge for a special need to bilateral communication in order to sociologically monitor their perception of general preventive actions, and to eventually readjust these actions to particular social conditions.

\section{Misleading communications}

Essential knowledge about transmission and prevention are widely communicated to community by all stakeholders, however, some messages could be misleading. Some inaccuracy could occur even by speechwriters of the presidental address to the nation which emphasized children among major infection carriers group.[48] In contrast, certain miscommunications have maliciously provocative forms with circulation of equivocal instructions in social media, or racial discrimination in paper media.[29] 
Psychological stress could lead to stigmatization of other people, discrimination, moralizing and searching for enemy to rationalize the exceptional threat posed by epidemic.[49][50] While the classic media have in general higher responsibility to not express these destructive manifestations, some users of social networks are less prone to follow ethical and humanistic standards that requires identifying and removing disease trolls and conspiracy advocates from major internet services.[51] At the same time, social media are vital shapers of the public's risk perception, especially useful for individuals without first-hand experience or knowledge of a health hazard.[52] Regarding this, the launch of WHO Health Alert service in WhatsApp is a crucial move to bring latest verified COVID-19 facts to billions of citizens.[53]

\section{Conclusion}

Initial governmental interaction with general public during was reasonably paternalistic, with provision of information about COVID-19 jeopardy and instructions for preventive measures. However, continuous gathering of feedback from general public and some vulnerable social groups is not routinely performed, that leaves uncertainty about the acceptance of preventive measures and social isolation behavior. We need to consider the epidemic from sociological point of view in addition to medical and economical perspectives as part of collective strategy that would further address trust and communication issues between authorities and population.

Stakeholders provide core information on the outbreak, but the latest scientific facts (for instance, the maximal duration of viral shedding) are not widely communicated to communities, although this could increase adhesion to actions deterring the epidemic. 
Widely accepted quarantine threshold of 14 days may mislead expectations toward the shortness of COVID-19 epidemic, while the emphasis on extended quarantine up to 40 days even after mild respiratory infection (in the absence of confirmatory negative COVID-19 RT-PCR test) could better prepare public opinion to longer period of extraordinary measures. A reshaped communication patterns would be especially important taking into account the approaching Easter holidays and arriving of spring in Northern hemisphere, both of which are traditionally related to higher socially activity.

These measures would increase compliance to quarantine rules, and help to prevent the second wave of epidemic, that may occur if risk perception decreases over time and persons with viral shedding resume face-to-face social contacts. 
Authors' contribution: authors contributed equally to this article.

Conflict of interests: none. 


\section{Bibliography}

1. Novel Coronavirus (COVID-19) Infection Map https://hgis.uw.edu/virus/.

2. Tanne JH, Hayasaki E, Zastrow M, Pulla P, Smith P, Rada AG. Covid-19: how doctors and healthcare systems are tackling coronavirus worldwide. BMJ. 2020 Mar 18;m1090. DOI: 10.1136/bmj.m1090, Available from:

http://www.bmj.com/lookup/doi/10.1136/bmj.m1090

3. Ebrahim SH, Ahmed QA, Gozzer E, Schlagenhauf P, Memish ZA. Covid-19 and community mitigation strategies in a pandemic. BMJ. 2020 Mar 17;m1066. DOI: 10.1136/bmj.m1066, Available from: http://www.bmj.com/lookup/doi/10.1136/bmj.m1066

4. Posetti J, Ireton C, Wardle C, Derakhshan H, Matthews A, Abu-Fadil M, et al. Journalism, fake news \& disinformation: handbook for journalism education and training. UNESCO, 2018. 128 p. ISBN: 978-92-3-100281-6 [Internet]. 2018. 128 p. Available from: https://unesdoc.unesco.org/ark:/48223/pf0000265552

5. Rosanvallon P, Goldhammer A. Counter-Democracy. Politics in an Age of Distrust. ISBN: 9780521886222. Cambridge University Press; 2008. 350 p.

6. WHO Q\&A on coronaviruses (COVID-19) [Internet]. Available from: https://www.who.int/news-room/q-a-detail/q-a-coronaviruses

7. Lauer SA, Grantz KH, Bi Q, Jones FK, Zheng Q, Meredith HR, et al. The Incubation Period of Coronavirus Disease 2019 (COVID-19) From Publicly Reported Confirmed Cases: Estimation and Application. Ann Intern Med. 2020 Mar 10; DOI: 10.7326/M200504, Available from: https://annals.org/aim/fullarticle/2762808/incubation-periodcoronavirus-disease-2019-covid-19-from-publicly-reported

8. Guan W, Ni Z, Hu Y, Liang W, Ou C, He J, et al. Clinical characteristics of 2019 novel coronavirus infection in China. MedRxiv. DOI: 10.1101/2020.02.06.20020974, 
9. Bai Y, Yao L, Wei T, Tian F, Jin D-Y, Chen L, et al. Presumed Asymptomatic Carrier Transmission of COVID-19. JAMA. 2020 Feb 21; DOI: 10.1001/jama.2020.2565, Available from: https://jamanetwork.com/journals/jama/fullarticle/2762028

10. Guan W, Ni Z, Hu Y, Liang W, Ou C, He J, et al. Clinical Characteristics of Coronavirus Disease 2019 in China. N Engl J Med. 2020 Feb 28;NEJMoa2002032. DOI: 10.1056/NEJMoa2002032, Available from: http://www.nejm.org/doi/10.1056/NEJMoa2002032

11. Zhou F, Yu T, Du R, Fan G, Liu Y, Liu Z, et al. Clinical course and risk factors for mortality of adult inpatients with COVID-19 in Wuhan, China: a retrospective cohort study. Lancet. 2020 Mar; DOI: 10.1016/S0140-6736(20)30566-3, Available from: https://linkinghub.elsevier.com/retrieve/pii/S0140673620305663

12. Liu Y, Yan L-M, Wan L, Xiang T-X, Le A, Liu J-M, et al. Viral dynamics in mild and severe cases of COVID-19. Lancet Infect Dis. 2020 Mar; DOI: 10.1016/S1473-3099(20)30232-2, Available from: https://linkinghub.elsevier.com/retrieve/pii/S1473309920302322

13. The Novel Coronavirus Pneumonia Emergency Response Epidemiology Team _. The Epidemiological Characteristics of an Outbreak of 2019 Novel Coronavirus Diseases (COVID-19) - China, 2020. China CDC Wkly. 2020;2(8):113-22. Available from: http://weekly.chinacdc.cn/en/article/id/e53946e2-c6c4-41e9-9a9b-fea8db1a8f51

14. Li R, Pei S, Chen B, Song Y, Zhang T, Yang W, et al. Substantial undocumented infection facilitates the rapid dissemination of novel coronavirus (SARS-CoV2). Science (80- ). 2020 Mar 16;eabb3221. DOI: 10.1126/science.abb3221, Available from: https://www.sciencemag.org/lookup/doi/10.1126/science.abb3221

15. Qiu J. Covert coronavirus infections could be seeding new outbreaks. Available from: https://www.nature.com/articles/d41586-020-00822-x

16. Rosenbaum L. Facing Covid-19 in Italy - Ethics, Logistics, and Therapeutics on the 
Epidemic's Front Line. N Engl J Med. 2020 Mar 18;NEJMp2005492. DOI:

10.1056/NEJMp2005492, Available from:

http://www.nejm.org/doi/10.1056/NEJMp2005492

17. Remuzzi A, Remuzzi G. COVID-19 and Italy: what next? Lancet. 2020 Mar; DOI: 10.1016/S0140-6736(20)30627-9, Available from:

https://linkinghub.elsevier.com/retrieve/pii/S0140673620306279

18. Controllate le celle telefoniche "Ancora il $40 \%$ delle persone in giro." L'eco di Bergamo. Available from: https://www.ecodibergamo.it/stories/bergamo-citta/controllate-le-celletelefonicheancora-il-40-delle-persone-in-giro_1345567_11/

19. European Comission. Standard Eurobarometer 92. Autumn 2019. National reports. Available from:

https://ec.europa.eu/commfrontoffice/publicopinion/index.cfm/Survey/getSurveyDetail/inst ruments/STANDARD/surveyKy/2255

20. WHO. Global research on coronavirus disease (COVID-19). Available from: https://www.who.int/emergencies/diseases/novel-coronavirus-2019/global-research-onnovel-coronavirus-2019-ncov

21. Chen $\mathrm{Y}$, Jin YL, Zhu LJ, Fang ZM, Wu N, Du MX, et al. [The network investigation on knowledge, attitude and practice about Novel coronavirus pneumonia of the residents in Anhui Province]. Zhonghua Yu Fang Yi Xue Za Zhi. 2020 Feb 17;54:E004. DOI: 10.3760/cma.j.issn.0253-9624.2020.0004, Available from: http://www.ncbi.nlm.nih.gov/pubmed/32064854

22. Nooh HZ, Alshammary RH, Alenezy JM, Alrowaili NH, Alsharari AJ, Alenzi NM, et al. Public awareness of coronavirus in Al-Jouf region, Saudi Arabia. J Public Health (Bangkok). 2020 Feb 13; DOI: 10.1007/s10389-020-01209-y, Available from: http://link.springer.com/10.1007/s10389-020-01209-y 
23. Geldsetzer P. Knowledge and Perceptions of COVID-19 Among the General Public in the United States and the United Kingdom: A Cross-sectional Online Survey. Ann Intern Med. 2020 Mar 20; DOI: 10.7326/M20-0912, Available from: https://annals.org/aim/fullarticle/2763550/knowledge-perceptions-covid-19-amonggeneral-public-united-states-united

24. Wang C, Pan R, Wan X, Tan Y, Xu L, Ho CS, et al. Immediate Psychological Responses and Associated Factors during the Initial Stage of the 2019 Coronavirus Disease (COVID-19) Epidemic among the General Population in China. Int J Environ Res Public Health. 2020 Mar 6;17(5):1729. DOI: 10.3390/ijerph17051729, Available from: https://www.mdpi.com/1660-4601/17/5/1729

25. Liu N, Zhang F, Wei C, Jia Y, Shang Z, Sun L, et al. Prevalence and predictors of PTSS during COVID-19 Outbreak in China Hardest-hit Areas: Gender differences matter. Psychiatry Res. 2020 Mar;112921. DOI: 10.1016/j.psychres.2020.112921, Available from: https://linkinghub.elsevier.com/retrieve/pii/S016517812030545X

26. Shigemura J, Ursano RJ, Morganstein JC, Kurosawa M, Benedek DM. Public responses to the novel 2019 coronavirus (2019 $\square \mathrm{nCoV}$ ) in Japan: Mental health consequences and target populations. Psychiatry Clin Neurosci. 2020 Feb 23;pcn.12988. DOI: 10.1111/pcn.12988, Available from: https://onlinelibrary.wiley.com/doi/abs/10.1111/pcn.12988

27. Bao Y, Sun Y, Meng S, Shi J, Lu L. 2019-nCoV epidemic: address mental health care to empower society. Lancet. 2020 Feb;395(10224):e37-8. DOI: 10.1016/S01406736(20)30309-3, Available from: https://linkinghub.elsevier.com/retrieve/pii/S0140673620303093

28. Mowbray H. In Beijing, coronavirus 2019-nCoV has created a siege mentality. BMJ. 2020 Feb 7;368:m516. DOI: 10.1136/bmj.m516, Available from: http://www.ncbi.nlm.nih.gov/pubmed/32033967 
29. Wen J, Aston J, Liu X, Ying T. Effects of misleading media coverage on public health crisis: a case of the 2019 novel coronavirus outbreak in China. Anatolia. 2020; DOI: 10.1080/13032917.2020.1730621, Available from:

https://doi.org/10.1080/13032917.2020.1730621

30. Liu S, Yang L, Zhang C, Xiang Y-T, Liu Z, Hu S, et al. Online mental health services in China during the COVID-19 outbreak. The Lancet Psychiatry. 2020 Apr;7(4):e17-8. DOI: 10.1016/S2215-0366(20)30077-8, Available from:

https://linkinghub.elsevier.com/retrieve/pii/S2215036620300778

31. Asmundson GJG, Taylor S. How health anxiety influences responses to viral outbreaks like COVID-19: What all decision-makers, health authorities, and health care professionals need to know. J Anxiety Disord. 2020 Apr;71:102211. DOI: 10.1016/j.janxdis.2020.102211, Available from: https://linkinghub.elsevier.com/retrieve/pii/S0887618520300256

32. Jang WM, Kim U-N, Jang DH, Jung H, Cho S, Eun SJ, et al. Influence of trust on two different risk perceptions as an affective and cognitive dimension during Middle East respiratory syndrome coronavirus (MERS-CoV) outbreak in South Korea: serial crosssectional surveys. BMJ Open. 2020 Mar 4;10(3):e033026. DOI: 10.1136/bmjopen-2019033026, Available from: http://www.ncbi.nlm.nih.gov/pubmed/32139484

33. Husnayain A, Fuad A, Su EC-Y. Applications of google search trends for risk communication in infectious disease management: A case study of COVID-19 outbreak in Taiwan. Int J Infect Dis. 2020 Mar; DOI: 10.1016/j.ijid.2020.03.021, Available from: https://linkinghub.elsevier.com/retrieve/pii/S1201971220301405

34. Zastrow M. South Korea is reporting intimate details of COVID-19 cases: has it helped? Nature. 2020 Mar 18; DOI: 10.1038/d41586-020-00740-y, Available from: http://www.nature.com/articles/d41586-020-00740-y

35. Maillé P. COVID-19 : "Il aurait fallu s'inspirer de Taïwan, mais c'est trop tard". Available 
from: https://usbeketrica.com/article/covid-19-il-aurait-fallu-s-inspirer-de-taiwan-mais-cest-trop-tard

36. Normile D. Coronavirus cases have dropped sharply in South Korea. What's the secret to its success? Science (80- ). 2020 Mar 17; DOI: 10.1126/science.abb7566, Available from: https://www.sciencemag.org/news/2020/03/coronavirus-cases-have-droppedsharply-south-korea-whats-secret-its-success

37. Rao ASRS, Vazquez JA. Identification of COVID-19 Can be Quicker through Artificial Intelligence framework using a Mobile Phone-Based Survey in the Populations when Cities/Towns Are Under Quarantine. Infect Control Hosp Epidemiol. 2020;1400:1-18. DOI: 10.1017/ice.2020.61, Available from:

http://www.ncbi.nlm.nih.gov/pubmed/32122430

38. Wang G, Zhang Y, Zhao J, Zhang J, Jiang F. Mitigate the effects of home confinement on children during the COVID-19 outbreak. Lancet. 2020 Mar;395(10228):945-7. DOI: 10.1016/S0140-6736(20)30547-X, Available from: https://linkinghub.elsevier.com/retrieve/pii/S014067362030547X

39. Coronavirus: A nursery rhyme can turn children's anxiety into a healthy habit. Available from: https://www.savethechildren.it/blog-notizie/coronavirus-non-solo-italiano-i-nostrisuggerimenti-diverse-lingue

40. Xie B, He D, Mercer T, Wang Y, Wu D, Fleischmann KR, et al. Global health crises are also information crises: A call to action. J Assoc Inf Sci Technol. 2020 Mar 13;asi.24357. DOI: 10.1002/asi.24357, Available from:

https://onlinelibrary.wiley.com/doi/abs/10.1002/asi.24357

41. Liem A, Wang C, Wariyanti Y, Latkin CA, Hall BJ. The neglected health of international migrant workers in the COVID-19 epidemic. The Lancet Psychiatry. 2020 Apr;7(4):e20. DOI: 10.1016/S2215-0366(20)30076-6, Available from: https://linkinghub.elsevier.com/retrieve/pii/S2215036620300766 
42. Bodomo A, Liem A, Lin L, Hall BJ. How African migrants in China cope with barriers to health care. Lancet Public Heal. 2020 Feb; DOI: 10.1016/S2468-2667(20)30048-7, Available from: https://linkinghub.elsevier.com/retrieve/pii/S2468266720300487

43. Castro HC, Lins Ramos AS, Amorim G, Ratcliffe NA. COVID-19: don't forget deaf people. Nature. 2020 Mar 17;579(7799):343-343. DOI: 10.1038/d41586-020-00782-2, Available from: http://www.nature.com/articles/d41586-020-00782-2

44. Iacobucci G. Covid-19: Doctors warn of humanitarian catastrophe at Europe's largest refugee camp. BMJ. 2020 Mar 17;m1097. DOI: 10.1136/bmj.m1097, Available from: http://www.bmj.com/lookup/doi/10.1136/bmj.m1097

45. Interim Guidance on Scaling-up COVID-19 Outbreak in Readiness and Response Operations in Camps and Camp-like Settings (jointly developed by IFRC, IOM, UNHCR and WHO). Available from: https://interagencystandingcommittee.org/other/interimguidance-scaling-covid-19-outbreak-readiness-and-response-operations-camps-andcamp

46. Tsai J, Wilson M. COVID-19: a potential public health problem for homeless populations. Lancet Public Heal. 2020 Mar; DOI: 10.1016/S2468-2667(20)30053-0, Available from: https://linkinghub.elsevier.com/retrieve/pii/S2468266720300530

47. Kinner SA, Young JT, Snow K, Southalan L, Lopez-Acuña D, Ferreira-Borges C, et al. Prisons and custodial settings are part of a comprehensive response to COVID-19. Lancet Public Heal. 2020 Mar; DOI: 10.1016/S2468-2667(20)30058-X, Available from: https://linkinghub.elsevier.com/retrieve/pii/S246826672030058X

48. L'adresse aux Français du Président de la République. Available from: https://www.elysee.fr/emmanuel-macron/2020/03/12/adresse-aux-francais

49. Loveday H. Fear, explanation and action - the psychosocial response to emerging infections. J Infect Prev. 2020 Mar 13;21(2):44-6. DOI: 10.1177/1757177420911511, 
Available from: http://journals.sagepub.com/doi/10.1177/1757177420911511

50. Ren S-Y, Gao R-D, Chen Y-L. Fear can be more harmful than the severe acute respiratory syndrome coronavirus 2 in controlling the corona virus disease 2019 epidemic. World J Clin Cases. 2020 Feb 26;8(4):652-7. DOI: 10.12998/wjcc.v8.i4.652, Available from: https://www.wjgnet.com/2307-8960/full/v8/i4/652.htm

51. Garrett L. COVID-19: the medium is the message. Lancet. 2020 Mar;395(10228):942-3. DOI: 10.1016/S0140-6736(20)30600-0, Available from: https://linkinghub.elsevier.com/retrieve/pii/S0140673620306000

52. Oh S-H, Lee SY, Han C. The Effects of Social Media Use on Preventive Behaviors during Infectious Disease Outbreaks: The Mediating Role of Self-relevant Emotions and Public Risk Perception. Health Commun. 2020 Feb 16;1-10. DOI:

10.1080/10410236.2020.1724639, Available from: https://www.tandfonline.com/doi/full/10.1080/10410236.2020.1724639

53. WHO Health Alert brings COVID-19 facts to billions via WhatsApp. Available from: https://www.who.int/news-room/feature-stories/detail/who-health-alert-brings-covid-19facts-to-billions-via-whatsapp 